\title{
EFFECTS OF DIETARY COMPOUND PROBIOTICS ON THE GROWTH PERFORMANCE AND INNATE IMMUNE RESPONSE OF NILE TILAPIA
}

\author{
MOHAMED AHMED IBRAHIM ${ }^{1}$; Z.H. ISMAIL ${ }^{1}$; WALAA F.A. EMEISH ${ }^{2}$ and H.A. HASSAN ${ }^{1}$ \\ ${ }^{1}$ Department of Poultry Production, Faculty of Agriculture, South Valley University \\ ${ }^{2}$ Department of Fish Diseases, Faculty of Veterinary Medicine, South Valley University
}

Received: 30 December 2018; Accepted: 30 January 2019

\begin{abstract}
This study was conducted to investigate the effect of addition of two commercial compound probiotics to the Nile tilapia fish`s diets on growth performance and distributed into 3 groups (control and 2 experimental) 30 fish each in three replicates. Fish were mentioned for adaptation in running water for 21 days. Duration of the experimental period was extended for 30 days. Fish were weighted at the beginning and at the end of the experiment. Blood samples were collected for determination of the immune and biochemical parameters. the results indicated a positive effect represented by significant increase in RBCs count, PCV\%, Hb Conc., WBCs and differential leukocytic count. The current study clearly demonstrated that compound probiotics can be used to modulate the immune response of Nile tilapia and to enhance the growth performance of Nile tilapia fish.
\end{abstract}

Key words: Nile tilapia; Compound Probiotics; Growth performance; Blood biochemistry; Non-specific immunity.

\section{INTRODUCTION}

Actually, with the growing human population, aquacultures in Egypt are growing fastest to compensate the shortage in animal protein. Among the cultured species was Nile tilapia, O. niloticus which is the potential and predominant cultured species around the world and comprises over $70 \%$ of the cultured tilapia (Fitzsimmons, 2000 and Fitzsimmons, 2004).

Several disease problems are accompanied by rapid growing and intensification of aquaculture, often due to opportunistic pathogens. Increased stocking densities with increased feeding rates and other organic loads enhances proliferation of opportunistic bacteria (Austin et al., 1995) inflicting adverse effects on fish health and production efficiency with consequent mass mortality.

Though the common response to prevention and control of diseases through the application of antibiotics and chemotherapy, the wide spread use of chemotherapeutics, especially antibiotics has resulted in emergency of drug resistant bacteria (Smith et al., 1994), accumulation of residual antibiotics in fish tissues (Harikrishnan et al., 2009a and Harikrishnan et al., 2009b) and environmental pollution

Corresponding author: WALAA F.A. EMEISH

E-mail address: Ibrahim.ahmed25@yahoo.com

Present address: Department of Poultry Production, Faculty of Agriculture, South Valley University
(Smith et al., 1994). Recently, in aquaculture, the use of probiotic bacteria to enhance the growth performance has received considerable attention. Using probiotics in aquaculture have been reported to provide beneficial effects (Balcázar et al., 2006) and the use of probiotics for enhancing bio-growth parameters has been well documented in fish (Robertson et al., 2000).

Numerous studies have shown that the addition of probiotics can improve feed conversion, growth rates and weight gain of salmonids (Merrifield et al., 2010). Probiotics are important for weight gain in fish (Aly et al., 2008, Cheng et al., 2014 and Dawood et al., 2015).

In tilapia, a number of commercial probiotics consisting of one or a mixture of bacteria such as Bacillus, Streptococcus, Lactobacillus or the commercial yeast Saccharomyces were used and reported higher growth performance and better immune response than the untreated fish (El-Haroun et al., 2006). Feed supplemented with multi-species probiotics is probably more effective than monospecies probiotics in provision of more diversity in antimicrobial component (Nayak, 2010a).

The use of multi-species probiotics as feed complements is probably more influential than mono-species probiotics in terms of more diversity in antimicrobial compounds and higher adhesion on the gut mucus (Nayak, 2010a). It has recently been shown that a mixture of Bacillus probiotics has 
significantly increased growth rate and body weight in the sea bream Sparusaurata (Avella et al., 2010). Generally, probiotics are mostly studied separately. Limited studies have contemplated the use of two or more bacteria as a probiotic mixture in fish (Nayak, 2010c and Dimitroglou et al., 2011). Two studies, of (Salinas et al., 2005 and Salinas et al., 2008) indicate that the two different bacteria could be more efficient and more proportionate than a single strain probiotic. Moreover, a combination of four bacteria was more beneficial to rainbow trout (Oncorhynchus mykiss) (Irianto and Austin, 2002). So, mixed cultures may contain bacteria that complement each other's health effect and thus differently modulate host immune responses (Dimitroglou et al., 2011).

Recently, lactic acid bacteria (LAB) probiotics as a feed supplement have been shown to be effective to modulate immunity and resistance against infectious diseases (Merrifield et al., 2010; Nayak 2010 b; Nayak 2010c and Dimitroglou et al., 2011).

Dietary administration of Lactobacillus spp. modulate the non-specific immune responses, growth and disease resistance of Nile tilapia ( $O$. niloticus) (Ngamkala et al., 2010).

The innate immune system of fish is very important which enables a rapid response against invading pathogens, and intensification of culture practices requires the use of external feed additives (Essa and Salama, 1994) to improve the growth performance and the immune response (Merrifield et al., 2010, Nayak 2010 b, Nayak 2010 c and Dimitroglou et al., 2011). Therefore, greater emphasis on application of probiotics in aquaculture is a better alternative to the drawbacks of using antibiotics (Watson et al., 2008).

The effect of probiotic on blood parameters have been studied in a number of studies (Merrifield $e t$ al., 2010). Hematological techniques have proved to be valuable for assessing the health of fish and monitoring stress responses. There were a range of factor that affect the hematological parameters of fish, among them the dietary regime used (Osuigwe et al., 2005).

The present experiment was conducted to evaluate the effects of addation two commercially available probiotic products, (Pro-bac plus and Amphi-bac), to Nile tilapia diets on the growth performance and some hemato- biochemical immune parameters.

\section{MATERIALS AND METHODS:}

Fish:

Nile tilapia, O. niloticus $(\mathrm{n}=90)$ were collected from a private fish farm in Qena province, Egypt. Fish were transported to the laboratory of Fish Diseases Department at Faculty of Veterinary Medicine, South
Valley University, Qena, Egypt. Fish were maintained under laboratory circumstances for adaptation in running water for 21 days depending on the protocol of maintaining bioassay fish as was previously described by Ellsaesser and Clem (1986) and kept in 9 plastic aquariums at density of 10 fish per aquarium. Fish were fed with basic diet during acclimation until the beginning of the experiment. Water change rate was seventy percent daily with dechlorinated stagnant tap water. Dissolved oxygen level was maintained by aeration above $5 \mathrm{mg} / \mathrm{L}$.

\section{Experimental diet:}

The basic diet was formulated physically to contain about grounded yellow corn $34.9 \%$, vegetable bean meal $28.6 \%$, fish meal $17.0 \%$, wheat bran $9.3 \%$, mineral mixture $1.7 \%$ and vitamin mixture $1.0 \%$. The basal diet was used as the control diet (diet 1). Two experimental diets (diet $2 \& 3$ ) were formulated from the basal diet. Apart of the basal diet was supplemented with commercial compound porobiotic at the rate of $5 \mathrm{gm} / \mathrm{kg}$ to form diet $2 \& 3$.

Probiotic product added to diet 2 contain

- LAB culture $2.0 \times 10^{7} \mathrm{CFU} / \mathrm{gm}$ total bacteria (Lactobacillus acidophilus, L. Planterum, $L$. Bervisand Bifidobacteria).

- Enzymes blend concentrate, Amylase 3.45 units/gm

- Beta- glucanase.

- Hemicellulase.

- Saccharomyces cervisiae 100mg/gm.

The second commercially available probiotic products (diet 3) contains:

- LAB culture $5.0 \mathrm{~g} / \mathrm{kg}$, provide a total of NLT $2.0 \times 10^{8} \mathrm{CFU} / \mathrm{gm}$ total bacteria $(50 \%$ Lactobacillus acidophilus $2.50 \mathrm{gm} / \mathrm{kg}, 49 \%$ L. planterum 2.45 $\mathrm{gm} / \mathrm{kg}$ and $1 \%$ Bifidobifidum $0.05 \mathrm{gm} / \mathrm{kg}$ ).

- Bacillus subtilus fermentation extracts $1.00 \mathrm{gm} / \mathrm{kg}$.

- Aspergillusniger fermentation extract $1.00 \mathrm{gm} / \mathrm{kg}$.

- Enzyme blend concentrate $2.00 \mathrm{gm} / \mathrm{kg}$, provide a total enzyme of 34.5 units/gm (37\% Amylase $1.46 \mathrm{gm} / \mathrm{kg}, 12 \%$ Cellulase $0.24 \mathrm{gm} / \mathrm{kg}, 6 \%$ Betaglucanase $0.12 \mathrm{gm} / \mathrm{kg}$ and $9 \%$ Hemicellulase $0.18 \mathrm{gm} / \mathrm{kg}$ ).

- Dextrose $993 \mathrm{gm} / \mathrm{kg}$.

The dietary ingredients were thoroughly mixed and stored at $-5^{\circ} \mathrm{C}$ until used and the required amount of the diet was prepared every week.

\section{Experimental design:}

Fish ( $n=90)$ were divided into 3 main groups, each group was divided into 3 replicates (10 fishes each):

- The first group was control $(n=30)$ fed on basic diet (diet 1),

- The second group $(n=30)$ fed on basic diet supplemented with 5 grams probiotic/ $\mathrm{kg}$ diet $(\operatorname{diet} 2)$ 
- The third group $(n=30)$ fed on basic diet supplemented with $5 \mathrm{gm}$ probiotic/ $\mathrm{kg}$ basal diet (diet 3).

Each group was fed twice daily at $3 \%$ of body weight for 30 successive days. The weight of the fish was recorded at the beginning and at 30- day of the experiment.

\section{Growth parameters:}

Body weight development:

Live body weight of fish was recorded at the beginning of the experiment and at the end of the experiment (30) days

\section{Body weight Gain:}

- BWG of fish was calculated by subtracting the live body weight at the beginning of the experiment (initial weight) from that at the end of the experiment initial weight of fish under experiment. (30days).

- BWG = Final weight - Initial weight

\section{Hematological studies:}

At the end the experiment ( 30 days), the weight of the fish was recorded and blood samples were collected from the caudal vein and divided into 2 portions. Sodium citrate $(3 \%)$ was added to one part for evaluation of Hemoglobin concentration, packed cell volume, differential leukocytic count and phagocytic assay.

The second part of blood sample was allowed to clot, centrifuged at $3000 \mathrm{rpm}$ for $15 \mathrm{~min}$. for serum separation.

Hemoglobin was assessed by a spectrophotometer (unico UV-2150) at $540 \mathrm{~nm}$ through the method cyanmethemoglobin, Hematocrit was measured by the procedure microcentrifuge with heparinated tubes (Svetina et al., 2002). Differential recognition of the WBC was based on blood films preparation and Gimsa staining. Blood cell indices (MCH, $\mathrm{MCV}$, and MCHC) were assessed according to the standard calculations described previously by (Campbell and Ellia, 2007).

Total serum proteins $(\mathrm{g} / \mathrm{dl})$ and albumin $(\mathrm{g} / \mathrm{dl})$ were determined by Protein and Albumin kits using colorimetric method according to manufacturer's recommendation. Globulin level (g/dl) was calculated mathematically by subtracting albumin value from total protein value (Busher, 1990).

\section{Phagocytosis assay:}

Phagocytic assay was conducted as per (Kawahara

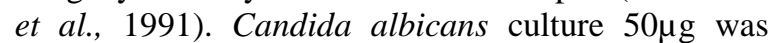
added to $1 \mathrm{ml}$ of citrated blood and shaken in water bath at $25^{\circ} \mathrm{C}$ for 5 hours. After that, smears of the blood were stained with Giemsa stain. Phagocytosis was evaluated by determining the proportion of phagocytic cells which contained intracellular yeast cells in a random count of 200 phagocytes (Abu-Elala et al., 2013) and expressed as percentage of phagocytic activity (PA). The phagocytic index (PI) was estimated by counting the number of phagocytized yeast cells in the phagocytic cells.

\section{Statistical analysis:}

All data were analyzed by one-way analysis of variance (ANOVA) using the general linear models procedure of statistical analysis system (SAS) version 8.02. Duncan's multiple range test (Duncan, 1955) was used to resolve differences among treatment means at $5 \%$ significant level.

\section{RESULTS}

Results of the blood immune parameters and weight gain of Nile tilapia (Oreochromis niloticus) which fed diets supplemented with Pro-bac plus or Amphi-bac are shown in (Table 1). Significant higher level of PCV and hemoglobin concentrations were recorded in fish fed on diets supplemented with probiotic products (diet $2 \& 3$ ) compared with the control.

Significant higher level of lymphocytes in fish received diet 3 probiotic than the control group, while neutrophil showed significant lower level than the other two groups.

Significant maximum phagocytic activity of Nile tilapia phagocytes was observed in fish received the diet 3 compound probiotic than the other two groups, while the phagocytic index was not significantly different for any diet group.

Significant higher values of total protein and globulin were recorded in fish groups received either type of probiotic diets, than that of control group, while albumin level showed significant decrease.

Fish in the second and third groups fed on diets containing probiotics products recorded significantly higher BWG than the control one. 
Table 1: Immune parameters and body weight gain of Nile tilapia as influenced by the different dietary treatments.

\begin{tabular}{cccc}
\hline Parameters & Basic diet & Pro-bac diet & Amphi-bac diet \\
\hline Hemoglobin gm/100ml & $2.5 \pm 0.1^{\mathrm{c}}$ & $3.6 \pm 0.1^{\mathrm{b}}$ & $4.03 \pm 0.2^{\mathrm{a}}$ \\
\hline PCV\% & $24.5 \pm 0.7^{\mathrm{c}}$ & $30.8 \pm 0.7^{\mathrm{b}}$ & $42.3 \pm 1.8^{\mathrm{a}}$ \\
\hline Lymphocyte \% & $41.4 \pm 3.4^{\mathrm{b}}$ & $42.2 \pm 1.8^{\mathrm{a}}$ & $47.8 \pm 1.5^{\mathrm{a}}$ \\
\hline Monocyte $\%$ & $27.4 \pm 2.3^{\mathrm{a}}$ & $31.6 \pm 2.1^{\mathrm{a}}$ & $31.8 \pm 2.2^{\mathrm{a}}$ \\
\hline Neutrophil \% & $18.2 \pm 1.2^{\mathrm{a}}$ & $15.4 \pm 1.8^{\mathrm{a}}$ & $13.6 \pm 1.8^{\mathrm{b}}$ \\
\hline Basophile $\%$ & $8.2 \pm 0.9^{\mathrm{a}}$ & $7.6 \pm 0.97^{\mathrm{a}}$ & $5.8 \pm 1.2^{\mathrm{a}}$ \\
\hline Eosinophil $\%$ & $4.8 \pm 0.5^{\mathrm{a}}$ & $3.2 \pm 0.7^{\mathrm{a}}$ & $28.3^{\mathrm{b}}$ \\
\hline Phagocytic $\%$ & $24.1 \pm 1.4^{\mathrm{a}}$ \\
\hline Phagocytic index & $21.7 \pm 0.98^{\mathrm{b}}$ & $1.13 \pm 0.03^{\mathrm{a}}$ \\
\hline Total protein mg/dl & $1.06 \pm 0.03^{\mathrm{a}}$ & $1.103 \pm 0.03^{\mathrm{a}}$ & $4.1 \pm 0.2^{\mathrm{a}}$ \\
\hline Albumin mg/dl & $3.32 \pm 0.1^{\mathrm{b}}$ & $4.46 \pm 0.2^{\mathrm{a}}$ & $1.26 \pm 0.1^{\mathrm{b}}$ \\
\hline Globulin mg/dl & $1.8 \pm 0.1^{\mathrm{a}}$ & $1.4 \pm 0.2^{\mathrm{b}}$ & $2.84 \pm 0.1^{\mathrm{a}}$ \\
\hline Total weight gain /gm & $1.5 \pm 0.2^{\mathrm{b}}$ & $3.06 \pm 0.3^{\mathrm{a}}$ & $11.8 \pm 1.5^{\mathrm{a}}$
\end{tabular}

Means in the same raw with different letters are significantly different $(\mathrm{p}<0.05)$.

\section{DISCUSSION}

Hematological data of the current study showed that HB and PCV were affected by probiotics used. Also (Marzouk et al., 2008a) found increases in HB value and PCV in fish groups fed with diet supplemented with probiotic (B. subtillis and Saccharomyces cerevisae). The increase in blood parameters could be attributed to the fact that, application of probiotics leads to hemopiotic stimulation.

Obtained results recorded that white blood cell count was increased in fish of the experimental groups in comparison with the control and this was an inevitable result because probiotics effect on immune system which might appear in white blood cell density (Panigrahi et al., 2005) and may increase phagocytosis (Picchietti et al., 2007).

The innate immune system of fish is the first line and primitive of defense against invading pathogens. The major components of the immune system are macrophages, monocytes, granulocytes, and humoral elements, such as immunoglobulins (Secombes and Fletcher, 1992 and Magnadóttir, 2006). Several types of leukocytes participate in the cellular immune response, including lymphocytes, monocytes, granulocytes (neutrophils, eosinophils and basophils), and cytotoxic cells (Nakanishi et al., 1999). Concerning the non-specific immune stimulation in $O$. niloticus fish groups received diets supplemented with probiotics. It was clear that high non-specific immunity was developed as manifested by increased number of lymphocytes and monocytes in the differential leucocytic count due to the activation of the hemopoietic tissues. In addition, recent studies indicated that probiotics can stimulate the piscine gut associated lymphoid tissue provoking an immune response (Nayak 2010a).

In the present study, better concentrations of $\mathrm{Hb}, \%$ haematocrit, $\mathrm{WBC}$, total serum protein, and serum globulin were observed in Nile tilapia maintained on the diet supplemented the two commercial diet used in the experiment, showing significant differences $(P<0.05)$ from the control. All leucocytes were counted as a percentage of the whole leucocytic count which constitutes $100 \%$, so either increase or decrease in different leucocytes was pronounced in fish. The decrease of the percentage of neutrophils in fish groups fed on Amphi-bac diet may be attributed to the significant increase of other leucocytic cells especially lymphocytes. Phagocytosis is a primary, non-specific defense mechanism against invasion of pathogenic organisms of hosts (Olivier et al., 1985). In the current study, Nile tilapia phagocytes showed increased the phagocytic activities when fed on either Pro-bac or Amphi-bac diets. The enhancement of phagocyte function is one of the most immediate and key effects produced by probiotics on the host immune system of fish. Previous studies demonstrated that aquatic animals fed probiotic had significantly increased phagocytic activity and index (Dias et al., 2010 and Harikrishnan et al. 2010). Increase in the percent of phagocytosis could be attributed to that probiotics used activate the phagocytic cells in the hemopiotic organs. The results indicated a significant increase in total protein and globulin in the second and third groups compared with the control group fed the basic diet. which could be attributed to the immuno- modulatory effect of Probac and Amphibac diets on the liver cells which activate the anabolic capacity of the hepatocytes to produce blood proteins particularly globulin. The present findings confirmed by those of Marzouk et al. 
(2008b); Zhou et al. (2010) and Chelladurai et al. (2013) who reported that total protein level was significantly increased by using probiotics and these results were supported by several authors Ortuño et al. (2002); and Safinaz (2006). With regard to the increase of the total protein and albumin in the treatment group, it can be concluded that the usage of the increase of the mentioned factors. In the confirmation of the above findings.

Significant increase in globulin in Pro-bac and Amphi-bac diets groups consequently lead to significant decrease in albumin, as globulin obtained by direct subtracting the values of the albumin from those of the total protein. Our results concured with speculations of other previous studies with regard to the total immunoglobulin concentration, where it was concluded that fish immunoglobulin concentration increases with probiotic in the diet. Increased total immunoglobulin concentration could be due to an increased immune response in the probiotic groups, induced by the presence of $L$. acidophilus, as suggested by Panigrahia et al. (2005).

Recently, it became known in aquaculture that probiotics in diets could help to improve fish growth. Among the various benefits of probiotics in aquaculture is the increased growth rate of fish (Ghosh et al., 2008 and Merrifield et al., 2009) and this could be confirmed in our experiment. This benefit is supposed to occur via the bacterial species colonizing the gut of the host as probiotics lead to a change in the bacterial composition of the gut that in some way benefits the health of the host (Balcazar et al., 2006 and El-Haroun et al., 2006).

In the present study, significantly $(P<0.05)$ better growth performance was observed in Nile tilapia maintained on the diet supplemented with the two commercial probiotics compared with fish of the control group fed on the basal diet. Ramesh et al. (2015) suggested that probiotics have beneficial effect on digestive operation because probiotic strains synthesize extracellular enzymes such as proteases, amylases and lipases, therefore, nutrients are absorbed more efficiently when the feed was supplemented with probiotics. Similar to our results, Lara-Flores et al. (2003) found that using yeast and the microbial mixture as feed supplement led to the best growth than those of control. Also Mohamed et al. (2007) reported thatfeeding diets supplemented by probiotic to fed Nile tilapia ( $O$. niloticus) fingerlings exhibited greater growth than those of control.

Improvement in growth performance when a commercial probiotics were used in fish diet, could be due to better nutrient digestibility, high-quality absorption and increased enzyme activities caused by a proper balance of the intestinal microbial flora
(Fuller, 1989) or exoenzyme secretion as suggested by Yanbo and Zirong (2006).

\section{CONCLUSION}

The present experiment showed that compound probiotic as feed supplement can be considered as an alternative method to overcome the drawbacks of chemotherapeutics for health improvement in aquaculture.

Results of the current study proved that dietary supplementation of Pro-bac or Amphi-bac diets enhanced the growth performance and the overall immune response of Nile tilapia as was indicated by the significant increase of the hematologic parameters, globulin proteins and the phagocytic activities of fish phagocytes.

\section{REFERENCES}

Abu-Elala, N.; Marzouk, M. and Moustafa, M. (2013): Use of different Saccharomyces cerevisiae biotic forms as immune modulator and growth promoter for Oreochromis niloticus challenged with some fish pathogens. International Journal of Veterinary Science and Medicine 1: 21-29.

Aly, S.M.; Mohamed, M.F. and John, G. (2008): Effect of probiotics on the survival, growth and challenge infection in Tilapia nilotica (Oreochromis niloticus). Aquaculture research, 39(6), 647-656.

Austin, B.; Stuckey, L.F.; Robertonm P.A.W.; Effendi, I. and Griffth, D.R.W. (1995): A probiotic strain of Vibrio alginolyticus effective in reducing diseases caused by Aeromonas salmonicida, Vibrio anguillarum and Vibrio ordalii. J Fish Dis 18: 93-96.

Avella, M.A.; Gioacchini, G.; Decamp, O.; Makridis, P.; Bracciatelli, C. and Carnevali, O. (2010): Application of multi-species of Bacillus in sea bream larviculture. Aquaculture 305:12-19

Balcázar, J.L.; De Blas, I.; Ruiz-Zarzuela, I.; Cunningham, D.; Vendrell, D. and Muzquiz, J.L. (2006): The role of probiotics in aquaculture. Veterinary microbiology, 114(34), 173-186.

Busher, J. (1990): Serum albumin and globulin. In: Walker HK, Hall WD, Hurst JW, editors. Clinical Methods: The History, Physical, and Laboratory Examinations. $3^{\text {rd }}$ edition. Boston: Butterworths.

Campbell, T.W. and Ellia, W.C. (2007): Avian and exotic animal haematology and cytology. 3rd edition. USA: Blackwell Publishing; 51-81.

Chelladurai, G.; Felicitta, J. and Nagarajan, $R$. (2013): Protective effect of probiotic diets on haematobiochemical and histopathology changes of Mystus montanus (Jerdon 1849) 
against Aeromonas hydrophila. Journal of Coastal Life Medicine, 1(4), 259-264.

Cheng, G.; Hao, H.; Xie, S.; Wang, X.; Dai, M.; Huang, L. and Yuan, Z. (2014): Antibiotic alternatives: the substitution of antibiotics in animal husbandry? Frontiers in microbiology, 5, 217.

Dawood, M.A.; Koshio, S.; Ishikawa, M. and Yokoyama, S. (2015): Interaction effects of dietary supplementation of heat-killed Lactobacillus plantarum and $\beta$-glucan on growth performance, digestibility and immune response of juvenile red sea bream, Pagrus major. Fish and shellfish immunology, 45(1), $33-42$.

Dias, D.D.C.; De Stéfani, M.V.; Ferreira, C.M.; França, F.M.; Ranzani-Paiva, M.J.T. and Santos, A.A. (2010): Haematologic and immunologic parameters of bullfrogs, Lithobates catesbeianus, fed probiotics. Aquaculture Research, 41(7), 1064-1071.

Dimitroglou, A.; Merrifield, D.L.; Carnevali, O.; Picchietti, S.; Avella, M., Daniels, G.; Guroy, D.; and Davies, S.J. (2011): Microbial manipulations to improve fish health and production-a Mediterranean perspective. Fish Shellfish Immunol. 30:1-16.

Duncan, D.B. (1955): Multiple Range and Multiple F-Test. Biometrics, 11: 1-42.

El-Haroun, E.R.; Goda, A.S. and Kabir Chowdhury, M.A. (2006): Effect of dietary probiotic Biogen ${ }^{\circledR}$ supplementation as a growth promoter on growth performance and feed utilization of Nile tilapia Oreochromis niloticus (L.). Aquaculture Research, 37(14), 1473-1480.

Ellsaesser, C.F. and Clem, L.W. (1986): Hematological and immunological changes in channel catfish by handing and transport. Journal of fish biology 28: 511-521

Essa, M.A. and Salama, M.E. (1994): Salinity tolerance and reproductive performance of Nile tilapia, Oreochromis niloticus. Delta J. Sci., 18: 239-261

Fitzsimmons, K. (2000): Tilapia: the most important aquaculture species of the 21 st century. In: Fitzsimmons, K. and Filho, J.C. (eds), Proceedings from the $5^{\text {th }}$ International Symposium on Tilapia Aquaculture, Vol. 1. Rio de Janeiro, Brazil, pp.3-8.

Fitzsimmons, K. (2004): Development of new products and markets for the global tilapia trade. In: Proceeding of the 6thInternational Symposium on Tilapia in Aquaculture, Manila, Philippines (ed. by R. Bolivar, G. Mair and K. Fitzsimmons), pp.624-633. BFAR, Philippines.

Fuller, R. (1989): Probiotic in man and animals. Journal of Applied Bacteriology, 66: 365-378.

Ghosh, S.; Sinha, A. and Sahu, C. (2008): Dietary probiotic supplementation in growth and health of live-bearing ornamental fishes. Aquac Nutr 14: 289-299.

Harikrishnan, $\quad$ R.; $\quad$ Balasundaram $\quad$.; Dharaneedharan S.Y.G.; Moon, Kim, M.C.; Kim, J.S. and Heo M.S. (2009a): Effect of plant active compounds on immune response and disease resistance in Cirrhina mrigala infected with fungal fish pathogen, Aphanomyces invadans. Aquacult. Res 40: $1170-1181$

Harikrishnan, R.; Balasundaram, C. and Heo, M.S. (2010): Effect of probiotics enriched diet on Paralichthys olivaceus infected with lymphocystis disease virus (LCDV). Fish Shellfish Immunol 29: 868-874.

Harikrishnan, R.; Balasundaram, C.; Kim, M.C.; Kim, J.S.; Han, Y.J. and Heo, M.S. (2009b): Innate immune response and disease resistance in Carassius auratus by triherbal solvent extracts. Fish and Shellfish Immunol 27: 508515.

Irianto, A. and Austin, B. (2002): Use of probiotics to control furunculosis in rainbow trout Oncorhynchus mykiss (Walbaum). J. Fish Dis. 25: 333-342

Kawahara, E.; Ueda, T. and Nomura, S. (1991): In vitro phagocytic activity of white spotted shark cells after injection with Aeromonas salmonicida extracelluar products. Fish Pathology, 26: 213-214.

Lara-Flores, M.; Olvera-Novoa, M.A.; GuzmanMendez, B.E. and Lopez-Madrid, W. (2003): Use of the bacteria Streptococcus faecium and Lactobacillus acidophilus and the yeast Saccharomyces cerevisiae as growth promoters in Nile tilapia (Oreochromis niloticus). Aquaculture 216: 193-201.

Magnadóttir, B. (2006): Innate immunity of fish (overview). Fish Shellfish Immunol 20: 137151.

Marzouk, M.S.; Moustafa, M.M. and Mohamed, N.M. (2008a): The influence of some probiotics on the growth performance and intestinal microbial flora of Oreochromis niloticus. Proceedings of the 8th International Symposium on Tilapia in Aquaculture, Cairo, Egypt, pp: 1059-1071.

Marzouk, M.S.; Moustafa, M.M. and Mohamed, N.M. (2008b): Evaluation of immunomodulatory effects of some probiotics on cultured Oreochromis niloticus. In 8th International symposium on tilapia in aquaculture (Vol. 1043).

Merrifield, D.L.; Bradley, G.; Baker, R.T.M. and Davies, S.J. (2009): Probiotic applications for rainbow trout (Oncorhynchus mykiss Walbaum) II. Effects on growth performance, feed utilization, intestinal microbiota and related health criteria postantibiotic treatment. Aqua Nutr. 
Merrifield, D.L.; Dimitroglou Foey, A.; Davies, S.J.; Baker, R.T.M. and Bogwald, J. (2010): The current status and future focus of probiotic and prebiotic applications for salmonids. Review Aquaculture 302: 1-18

Mohamed, K.A.; Fattah, B.A. and Eid, A.M.S. (2007): Evaluation of using some feed additives on growth performance and feed utilization of monosex Nile tilapia (Oreochromis niloticus) fingerlings. Agricultural Research Journal, Suez Canal University 7(3): 49-54

Nakanishi, T.; Aoyagi, K.; Xia, C.; Dijkstra, J.M.; and Ototake, M. (1999): Specific cellmediated immunity in fish. Vet Immunol Immunopathol 72: 101-109.

Nayak, S.K. (2010a): Probiotics and immunity: A fish perspective. Fish Shellfish Immunol 29: 2-14.

Nayak, S.K. (2010b): Role of gastrointestinal microbiota in fish. Aquac. Res 41: 15531573.

Nayak, S.K. (2010c): Probiotics and immunity: a fish perspective. Fish Shellfish Immunol. 29 (2-14).

Ngamkala, S.; Futami, K.; Endo, M.; Maita, M. and Katagiri, T. (2010): Immunological effects of glucan and Lactobacillus rhamnosus GG, a probiotic bacterium, on Nile tilapia Oreochromis niloticus intestine with oral Aeromonas challenges. Fisheries Sci., 76: 833-840.

Olivier, G.; Evelyn, T.P.T. and Lallier, R. (1985): Immunogenicity of vaccines from a virulent and an a virulent strain of Aeromonas salmonicida. Journal of Fish Diseases, 8(1), 43-55.

Ortuño, J.; Cuesta, A.; Rodríguez, A.; Esteban, M.A. and Meseguer, J. (2002): Oral administration of yeast, Saccharomyces cerevisiae, enhances the cellular innate immune response of gilthead seabream (Sparus aurata L.). Veterinary immunology and immunopathology, 85(1-2), 41-50.

Osuigwe, D.I.; Obiekezie, A.I. and Onuoha, G.C. (2005): Some haematological changes in hybrid catfish (Heterobranchus longifilis $\mathrm{x}$ Clarias gariepinus) fed different dietary levels of raw and boiled jackbean (Canavalia ensiformis) seed meal. Afri. J. Biotech, 4(9): 017-1021.

Panigrahi, A.; Kiron, V.; Puangkaew, J.; Kobayashi, T.; Satoh, S. and Sugita, H. (2005): The viability of probiotic bacteria as a factor influencing the immune response in rainbow trout Oncorhynchus mykiss. Aquaculture, 243(1-4), 241-254.

Picchietti, S.; Mazzini, M.; Taddei, A.R.; Renna, R.; Fausto, A.M.; Mulero, V.; Carnevali, O.; Cresci, A. and Abelli, L. (2007): Effects of administration of probiotic strains on GALT of larval gilthead seabream: immunohistochemical and ultrastructural studies. Fish and Shellfish Immunology, 22 (12), 57-67.

Ramesh, D.; Vinothkanna, A.; Rai, A.K. and Vignesh, V.S. (2015): Isolation of potential probiotic Bacillus spp. and assessment of their subcellular components to induce immune responses in Labeo rohita against Aeromonas hydrophila. Fish and shellfish immunology, 45(2), 268-276.

Robertson, P.A.W.; O'Dowd, C.; Burrells, C.; Williams, P. and Austin, B. (2000): Use of Carnobacterium sp. as a probiotic for Atlantic salmon (Salmo salar L.) and rainbow trout (Oncorhynchus mykiss, Walbaum). Aquaculture, 185(3-4), 235-243.

Safinaz, R.A.A. (2006): clinicopathological studies on the effect of growth promoters in Nile tilapia. MV Sc (Doctoral dissertation, Thesis, Faculty of Veterinary Medicine, Cairo University).

Salinas, I.; Abelli, L.; Bertoni, F.; Picchietti, S.; Roque, A.; Furones, D.; Cuesta, A.; Meseguer, J. and Esteban, M.A. (2008): Monospecies and multispecies probiotic formulations produce different systemic and local immunostimulatory effects in the gilthead seabream (Sparusaurata L.). Fish Shellfish Immunol. 25: 114-123.

Salinas, I.; Cuesta, A.; Esteban, M.A. and Meseguer, J. (2005): Dietary administration of Lactobacillus delbrueckii and Bacillus subtilis, single or combined, on gilthead seabream cellular innate immune responses. Fish Shellfish Immunol., 19: 67-77.

Secombes, C.J. and Fletcher, T.C. (1992): The role of phagocytes in the protective mechanisms of fish. Annual Review of Fish Diseases 2: 53-71.

Smith, P.; Hiney, M.P. and Samuelesenm O.B. (1994): Bacterial resistance to antimicrobial agent used in fish farming: a critical evaluation of method and meaning. Annu. Rev. Fish Dis 4: 273-313.

Svetina, A.; Matasin, Z.; Tofant, A.; Vucemilo, M. and Fijan, N. (2002): Hematology and some blood chemical parameters of young carp till the age of three years. Acta Vet Hung 50: 459-467.

Watson, A.K.; Kaspar, H.; Lategan, M.J. and Gibson, L. (2008): Probiotics in aquaculture. The need, principles and mechanisms of action and screening processes. Aquaculture 274: 1-14.

Yanbo, W.; and Zirong, X. (2006): Effect of probiotics for common carp (Cyprinus carpio) based on growth performance and digestive enzyme activities. Animal feed science and technology, 127(3-4), 283-292.

Zhang, Q.; Ma, H.; Mai, K.; Zhang, W.; Liufu, Z. and $X u, W$. (2010): Interaction of dietary Bacillus subtilis and fructooligosaccharide on the growth performance, non-specific immunity of 
sea cucumber, Apostichopus japonicus. Fish and Shellfish Immunology, 29(2), 204-211.

Zhou, X.; Wang, Y.; Yao, J. and Li, W. (2010): Inhibition ability of probiotic, Lactococcus lactis, against A. hydrophila and study of its immunostimulatory effect in tilapia (Oreochromis niloticus). International Journal of Engineering, Science and Technology, 2(7).

\section{تاثير التغذية بالبروبيوتك المركب على أداء النمو والاستجابة المناعية لاسماك البلطى النيلى

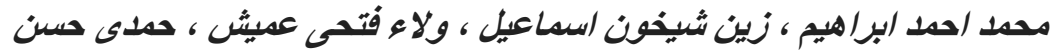

Email: Ibrahim.ahmed25@yahoo.com Assiut University web-site: www.aun.edu.eg

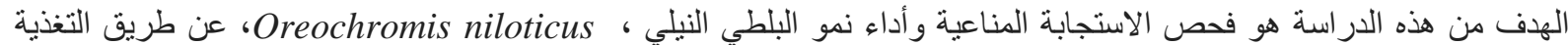

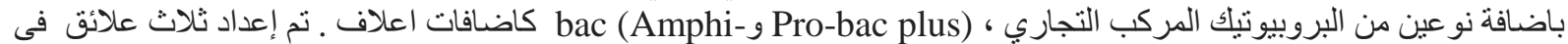

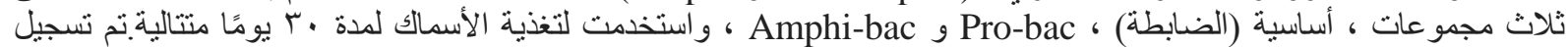

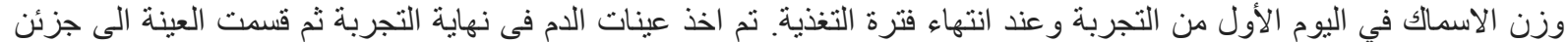

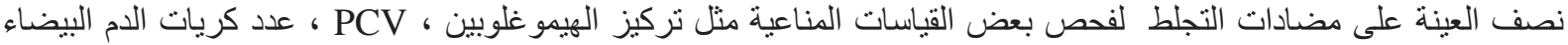

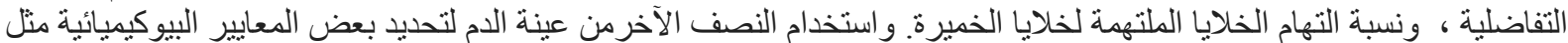

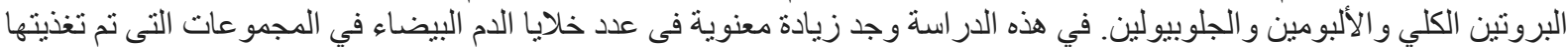

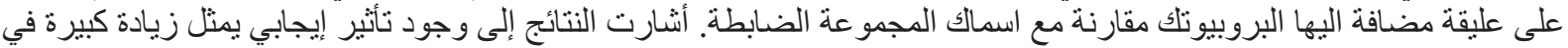

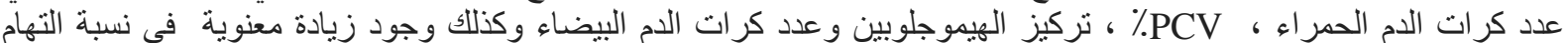

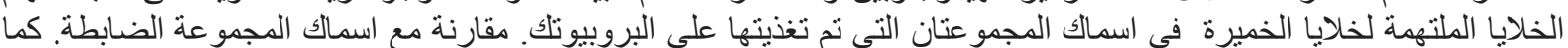

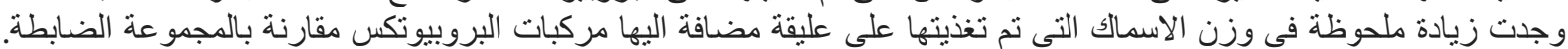
واظهرت الدر اسة الحالية أن البروبيوتيك المركب يمكن استخدامه لتحسين الاستجابة المناعية للبلطي النيلي ولتعزيز البراء أداء النمو. 